\title{
Bocavirus humano: Estudios en la literatura médica y en Chile
}

\author{
Claudia Moreno M., Yanahara Solís O. y Miguel O 'Ryan G.
}

\begin{abstract}
Facultad de Medicina,
Universidad de Chile

Unidad de Microbiología (CMM)

Programa de Microbiología y

Micología ICBM (MOG)

Hospital Luis Calvo Mackenna,

Santiago, Chile

Unidad de Infectología Pediátrica,
\end{abstract} (YSO)

Los autores declaran no tener conflictos de interés

El presente trabajo no tiene financiamiento

Recibido: 23 de junio de 2009 Aceptado: 4 de agosto de 2009

Correspondencia a: Claudia Moreno Moreno clau.moreno.m@gmail.com

\section{Introducción}

B ocavirus humano (HBoV) es un virus descrito por primera vez en el año 2005 por Allander y cols ${ }^{1}$, identificado en muestras de aspirado nasofaríngeo (ANF) en niños con infecciones del tracto respiratorio inferior. El virus fue descubierto por métodos moleculares, utilizando un sistema de amplificación no específica y clonación de la secuencia genómica viral de un parvovirus humano previamente no descrito. El virus fue aislado en secreciones respiratorias procedentes de lactantes y niños suecos con manifestaciones clínicas de enfermedad del tracto respiratorio.

Las secuencias genéticas y el análisis filogenético muestran una estrecha relación de $\mathrm{HBoV}$ con dos miembros de la familia Parvoviridae: parvovirus bovino (BPV) y virus minute canino $(\mathrm{CMnV})$, por lo que recibió el nombre provisorio de bocavirus humano (HBoV), "bo" de bovino y "ca" de canino".

Desde su detección el 2005, múltiples estudios a nivel mundial han reportado la presencia de $\mathrm{HBoV}$ en muestras del tracto respiratorio en niños y adultos, detectándose también en muestras fecales, sanguíneas y urinarias. En infección respiratoria se describe una prevalencia de $2,7 \%^{1}$ a $19 \%(\text { Suecia })^{2}$ principalmente en niños bajo dos años de edad. Estas diferencias pueden explicarse por la estacionalidad, predominando en invierno, y por las distintas poblaciones de los estudios. En muestras fecales de pacientes con gastroenteritis aguda existe una prevalencia de $0,8 \%$ (Corea del Sur) $^{3}$ a 9,1\% (España) $)^{4}$. Muestras séricas positivas ${ }^{3}$ para $\mathrm{HBoV}$ sugieren que la infección tiene un componente sistémico, tal como la mayoría de parvovirus veterinarios y parvovirus B19 (B19V).

Existen datos sobre prevalencia en individuos asintomáticos: un estudio canadiense ${ }^{5}$ no encontró detección de ADN viral en pacientes sanos controles; otro estudio español ${ }^{6}$ describe detección de genoma viral en $5 \%$ de muestras respiratorias en niños asintomáticos y el estudio de Longtin y cols ${ }^{7}$, destaca porque $43 \%$ de niños asintomáticos hospitalizados para cirugía electiva presentaron muestras respiratorias positivas para $\mathrm{HBoV}$.

Varios estudios reportan un alto porcentaje de coinfección con otros virus lo que ha llevado a cuestionar su rol como patógeno respiratorio. Este cuestionamiento de un rol patogénico real se sustenta también en la alta tasa de portación descrita en Canadá7.

Actualmente, $\mathrm{HBoV}$ y B19V serían los dos únicos miembros de esta familia viral que causan enfermedades en humanos: B19V responsable de eritema infeccioso en niños e hidrops fetal en infecciones intrauterinas y $\mathrm{HBoV}$ como agente viral de infecciones del tracto respiratorio, principalmente en niños bajo 5 años de edad.

\section{Estructura}

Los virus de la familia Parvoviridae son de pequeño tamaño (20-26 nm), de simetría icosaédrica y no poseen manto, su genoma está formado por ADN de simple hebra y es dependiente de células en división para la replicación 
viral. El genoma viral de $\mathrm{HBoV}$ contiene información genética para proteínas estructurales y no estructurales.

Los genes de proteínas no estructurales representan regiones conservadas, mientras que los genes que codifican para proteínas de cápside presentan mayor variabilidad.

Los parvovirus poseen dos proteínas estructurales: las proteinas virales 1 (VP1) y 2 (VP2), idénticas en secuencia, que sólo difieren en la región amino-terminal de VP1, conocida como región única de VP1 (VP1u). En HBoV esta región posee 129 aminoácidos y tiene actividad de fosfolipasa A2, que es importante para la capacidad infectante viral, favoreciendo la entrada al núcleo de la célula hospedera para iniciar la replicación viral ${ }^{8}$.

\section{Clasificación}

La organización genómica de $\mathrm{HBoV}$ se relaciona a dos virus de la subfamilia Parvovirinae: virus minute canino $(\mathrm{CMnV})$ y parvovirus bovino (BPV), ambos virus veterinarios, y el International Committee on Taxonomy of Viruses reagrupó estos tres virus en un nuevo género llamado Bocavirus. El nuevo virus identificado, denominado como bocavirus humano $(\mathrm{HBoV})$, muestra separación filogenética de $\mathrm{CMnV}$ y BPV, presentando una identidad de sólo 43 y $42 \%$ con CMnV y BPV, respectivamente'.

$\mathrm{HBoV}$ fue clasificado en la familia Parvoviridae, subfamilia Parvovirinae y género Bocavirus (Tabla 1).

\section{Evidencia en que se sustenta el rol patogénico de $\mathrm{HBoV}$}

La mayoría de estudios publicados han sido realizados de manera retrospectiva, en muestras de ANF de pacientes con estudio negativo para adenovirus (ADV), influenza, parainfluenza, virus respiratorio sincicial (VRS) y metapneumovirus humano (MPVh). Diferentes estudios han reportado una incidencia que varía desde 1,5 a 18,3\% en individuos con infecciones respiratorias agudas bajas, siendo más frecuente en lactantes y con un predominio estacional en invierno y primavera ${ }^{9}$ (Tabla 2 ).

Un estudio realizado en niños con sibilancias espiratorias agudas de Finlandia ${ }^{10}$, investigó 16 virus en 259 muestras de ANF y sangre, mostrando como resultados que $95 \%$ tuvo, al menos, un agente etiológico viral y que más de un agente viral fue detectado en $34 \%$, y de estos 49 niños $(19 \%)$ fueron $\mathrm{HBoV}(+)$; la mayoría, sin embargo, fueron infecciones mixtas y $\mathrm{HBoV}$ como agente único se detectó en 12 niños (5\%). Además se observó cargas virales altas de $\mathrm{HBoV}$ en ausencia de otros virus, lo que sugiere un posible rol causal de las sibilancias. En este estudio, la mayoría de los niños con $\mathrm{HBoV}$ positivo en secreciones fueron también positivos en suero $(53,5 \%)$ mientras que sólo $7 \%$ de los niños con $\mathrm{HBoV}$ negativo en secreciones resultó $\mathrm{HBoV}$ positivo en suero. Este estudio concluyó que: $\mathrm{HBoV}$ es prevalente entre los niños con sibilancias agudas; puede causar infección sistémica al igual que otros parvovirus y persistir después de la resolución de los síntomas; cargas virales altas están potencialmente asociadas con síntomas respiratorios; el gran número de infecciones mixtas puede indicar que el $\mathrm{HBoV}$ es reactivado o su detección aumenta con otras infecciones.

La mayoría de los estudios muestra que la co-infección con otros virus respiratorios es común, y algunos evidencian $\mathrm{HBoV}$ en el suero, lo que sugiere viremia durante la infección. Otros estudios reportan que varios de los niños con $\mathrm{HBoV}$ tuvieron diarrea, sugiriendo que la enfermedad se extiende más allá del tracto respiratorio ${ }^{11}$. La descripción de niños infectados con $\mathrm{HBoV}$ que presentaron diarrea, sumado a la relación cercana de este virus con parvovirus bovino y el virus minute canino que infectan animales y causan enfermedad intestinal manifestada por vómitos, anorexia, letargia y diarrea con rápida deshidratación, hicieron plantear que este virus podría tener también un rol en enfermedades gastrointestinales en el humano y que podría ser detectado en muestras fecales ${ }^{12,13}$.

Maggi y cols ${ }^{14}$, describió por primera vez un lactante con bronquiolitis en el que se detectó ADN de $\mathrm{HBoV}$ también en heces, y a partir del año 2007 hasta la actualidad se reporta un número de estudios que sugieren que el HBoV podría afectar el tracto gastrointestinal, pero sin pruebas definitivas ${ }^{15-20}$. Así, Vicente y cols ${ }^{4}$, investigando la presencia de virus en niños con infección respiratoria en España, reportó en dos niños de 12 meses de edad con diarrea aguda, además de síntomas respiratorios, la presencia de $\mathrm{HBoV}$ en deposiciones, en ausencia de otro patógeno detectable. Debido a la posibilidad de que la detección en deposiciones fuese consecuencia de contaminación fecal por deglución de secreciones respiratorias y no de una infección intestinal primaria, se realizó un nuevo estudio buscando la presencia de $\mathrm{HBoV}$ en muestras fecales. Se detectó $\mathrm{HBoV}$ en 48 niños $(9,1 \%)$, y de éstos $28(58,3 \%)$ mostraron co-infección con otro patógeno intestinal, concluyendo que: $\mathrm{HBoV}$ está presente en el tracto gastrointestinal de niños con gastroenteritis, con o sin síntomas de infección respiratoria; la excreción fecal suma una nueva preocupación en relación a la transmisión de $\mathrm{HBoV}$; la alta frecuencia de detección de $\mathrm{HBoV}$ en las

Tabla 1. Taxonomía del género Bocavirus

\begin{tabular}{|c|c|c|c|}
\hline Subfamilia & Género & Especie humana & Especie veterinaria \\
\hline Parvovirinae & Bocavirus & $\begin{array}{l}\text { Bocavirus humano } \\
\text { (HBoV) }\end{array}$ & $\begin{array}{l}\text { Virus minute canino (CMnV) } \\
\text { Parvovirus bovino (BPV) }\end{array}$ \\
\hline
\end{tabular}




\section{Tabla 2. Evidencia de infección de HBoV en el tracto respiratorio}

\begin{tabular}{|c|c|c|c|c|c|c|c|c|c|}
\hline Autor & $\begin{array}{l}\text { Año de } \\
\text { publi- } \\
\text { cación }\end{array}$ & $\begin{array}{l}\text { País de } \\
\text { estudio }\end{array}$ & $\begin{array}{l}\text { Tipo de } \\
\text { estudio }\end{array}$ & $\begin{array}{l}\text { Criterios de } \\
\text { selección }\end{array}$ & $\begin{array}{l}\text { Tipo de } \\
\text { muestra }\end{array}$ & $\begin{array}{c}\text { n de } \\
\text { muestras }\end{array}$ & $\begin{array}{l}\text { Positividad } \\
\text { bocavirus } \\
(\%)\end{array}$ & $\begin{array}{c}\text { Coinfección } \\
\text { (\%) }\end{array}$ & Conclusión \\
\hline Allander ${ }^{1}$ & 2005 & Suecia & $\begin{array}{l}\text { Análisis } \\
\text { molecular }\end{array}$ & $\begin{array}{l}\text { ITR, } \\
\text { sibilancias, } \\
\text { asma }\end{array}$ & $\begin{array}{l}\text { Secreción } \\
\text { respiratoria }\end{array}$ & 540 & 2,7 & 17,6 & $\begin{array}{l}\text { Primer estudio de identifi- } \\
\text { cación de HBoV }\end{array}$ \\
\hline Arden $^{25}$ & 2006 & Australia & $\begin{array}{l}\text { Cohorte } \\
\text { retrospectiva }\end{array}$ & ITRI & $\begin{array}{l}\text { Secreción } \\
\text { respiratoria }\end{array}$ & 315 & 4,8 & 67 & $\begin{array}{l}\text { HBoV es el cuarto virus en } \\
\text { ITR en niños hospitalizados }\end{array}$ \\
\hline Bastien $^{5}$ & 2006 & Canadá & $\begin{array}{l}\text { Cohorte } \\
\text { retrospectiva }\end{array}$ & ITR < 17 años & $\begin{array}{l}\text { Secreción } \\
\text { respiratoria }\end{array}$ & 1.265 & 5,1 & - & $\begin{array}{l}\text { Rol en ITR en niños pe- } \\
\text { queños }\end{array}$ \\
\hline Arnold ${ }^{20}$ & 2006 & E.U.A. & $\begin{array}{l}\text { Cohorte } \\
\text { retrospectiva }\end{array}$ & $\begin{aligned} & \text { ITR en } \\
< & 12 \text { meses }\end{aligned}$ & $\begin{array}{l}\text { Hisopado } \\
\text { nasal }\end{array}$ & 1.474 & 5,6 & 12 & $\begin{array}{l}\text { HBoV está presente en ITR } \\
\text { en niños }\end{array}$ \\
\hline Manning ${ }^{32}$ & 2006 & Reino Unido & $\begin{array}{l}\text { Cohorte } \\
\text { retrospectiva }\end{array}$ & $\begin{array}{l}\text { Niños con } \\
\quad \text { ITRI }\end{array}$ & $\begin{array}{l}\text { Secreción } \\
\text { respiratoria }\end{array}$ & 574 & 8,2 & 43 & $\begin{array}{l}\text { HBoV puede ser un pató- } \\
\text { geno respiratorio poten- } \\
\text { cial, comparable a VRS }\end{array}$ \\
\hline Regamey $^{24}$ & 2007 & Suiza & $\begin{array}{c}\text { Cohorte } \\
\text { prospectiva }\end{array}$ & $\begin{array}{l}\text { Primer } \\
\text { episodio } \\
\text { de ITR en } \\
<3 \mathrm{~m}\end{array}$ & $\begin{array}{l}\text { Secreción } \\
\text { respiratoria }\end{array}$ & 113 & 4,5 & 80 & $\begin{array}{l}\text { HBoV circula en la co- } \\
\text { munidad y se adquiere } \\
\text { temprano }\end{array}$ \\
\hline $\operatorname{Lin}^{26}$ & 2007 & China & $\begin{array}{l}\text { Cohorte } \\
\text { retrospectiva }\end{array}$ & ITRI & $\begin{array}{l}\text { Secreción } \\
\text { respiratoria }\end{array}$ & 257 & 2,7 & - & $\begin{array}{l}\text { Agente etiológico en ITRI } \\
\text { en China }\end{array}$ \\
\hline Fry $^{31}$ & 2007 & Tailandia & Caso-control & ITRS & $\begin{array}{l}\text { Secreción } \\
\text { respiratoria }\end{array}$ & $\begin{array}{c}\text { Casos: } 512 \\
\text { Controles: } \\
280\end{array}$ & $\begin{array}{l}\text { Casos: } 3,9 \\
\text { Controles: } 1\end{array}$ & $\begin{array}{c}\text { Casos: } 83 \\
\text { Controles: } 90\end{array}$ & $\begin{array}{l}\text { HBoV está asociado a neu- } \\
\text { monía en niños pequeños, } \\
\text { depende de coinfección }\end{array}$ \\
\hline Allander ${ }^{2}$ & 2007 & Suecia & $\begin{array}{c}\text { Cohorte } \\
\text { prospectiva }\end{array}$ & Sibilancias & $\begin{array}{l}\text { Secreción } \\
\text { respiratoria, } \\
\text { séricas }\end{array}$ & 259 & 19 & 5 & $\begin{array}{l}\text { HBoV es prevalente en ni- } \\
\text { ños con sibilancias y puede } \\
\text { causar infección sistémica }\end{array}$ \\
\hline $\operatorname{Lau}^{28}$ & 2007 & Hong Kong & $\begin{array}{c}\text { Estudio } \\
\text { prospectivo } \\
\text { clínico y } \\
\text { molecular }\end{array}$ & ITR y GEA & $\begin{array}{l}\text { Secreción } \\
\text { respiratoria y } \\
\text { deposición }\end{array}$ & $\begin{array}{c}\text { Respiratorio: } \\
1.200 \\
\text { Fecal: } 1.435\end{array}$ & $\begin{array}{c}\text { Respiratorio: } \\
6,9 \\
\text { Fecal: } 2,1\end{array}$ & $\begin{array}{l}\text { Respiratorio: } \\
33 \\
\text { Fecal: } 56\end{array}$ & $\begin{array}{l}\text { Una sola cepa de HBoV se } \\
\text { asoció a ITR y GEA }\end{array}$ \\
\hline Rihkanem ${ }^{10}$ & 2008 & Finlandia & Caso-control & $\begin{array}{l}\text { Niños con } \\
\text { voz ronca y } \\
\text { estridor } \\
\text { inspiratorio }\end{array}$ & $\begin{array}{l}\text { Secreción } \\
\text { respiratoria }\end{array}$ & $\begin{array}{l}\text { Casos: } 144 \\
\text { Controles: } 76\end{array}$ & $\begin{array}{c}\text { Casos: } 12,5 \\
\text { Controles: } \\
10,5\end{array}$ & 72 & $\begin{array}{l}\text { Presencia de HBoV similar } \\
\text { en ambos grupos. Coinfec- } \\
\text { ción viral frecuente }\end{array}$ \\
\hline
\end{tabular}

ITR: Infección del tracto respiratorio, ITRS: Infección del tracto respiratorio superior, ITRI: Infección del tracto respiratorio inferior, GEA: Gastroenteritis aguda

heces de niños con gastroenteritis y la ausencia de algún otro patógeno intestinal sugieren que esta nueva especie de virus es un patógeno entérico, así como respiratorio (Tabla 3).

La distribución actualmente reconocida de $\mathrm{HBoV}$ es universal, con detección en Alemania, Australia, Canadá, China, Corea del Sur, España, E.U.A., Francia, Japón, Jordania, Sudáfrica y Tailandia ${ }^{21}$. Sin embargo, a pesar de los hallazgos ya mencionados, el espectro clínico de la enfermedad y el rol causal de este virus permanecen inciertos.

\section{Estudios en Chile}

Existen dos estudios de HBoV humano en muestras de hisopado nasofaríngeo (HNF) en niños (Tabla 4). En el primer estudio, JC Flores y cols $^{22}$, examinaron 256 mues- 
Tabla 3. Estudios que señalan evidencia de HBoV en cuadros gastrointestinales

\begin{tabular}{|c|c|c|c|c|c|c|c|c|c|}
\hline Autor & $\begin{array}{l}\text { Año de } \\
\text { publica- } \\
\text { ción }\end{array}$ & $\begin{array}{l}\text { País de } \\
\text { estudio }\end{array}$ & $\begin{array}{l}\text { Tipo de } \\
\text { estudio }\end{array}$ & $\begin{array}{l}\text { Criterios de } \\
\text { selección }\end{array}$ & $\begin{array}{l}\text { Tipo de } \\
\text { muestra }\end{array}$ & $\begin{array}{c}\text { n de } \\
\text { muestras }\end{array}$ & $\begin{array}{c}\text { Positividad } \\
\text { bocavirus } \\
\text { (\%) }\end{array}$ & $\begin{array}{c}\text { Coinfección } \\
(\%)\end{array}$ & Conclusión \\
\hline $\begin{array}{l}\text { Albur- } \\
\text { querque }^{12}\end{array}$ & 2007 & Brasil & Descriptivo & $\begin{array}{l}<15 \text { años } \\
\text { SDA } \\
\text { Sin síntomas } \\
\text { respiratorios } \\
\text { hospitalizados } \\
\text { ambulatorios } \\
\text { servicio urgencia }\end{array}$ & $\begin{array}{l}\text { Muestras } \\
\text { fecales }\end{array}$ & 705 & 2 & 21,4 & $\begin{array}{l}\text { Detección de altos títulos de } \\
\text { ADN, sugiere replicación viral } \\
\text { en intestino } \\
\text { Recomiendan estudios que } \\
\text { incluyan grupos caso-control } \\
\text { para determinar asociación }\end{array}$ \\
\hline Vicente $^{4}$ & 2007 & España & Descriptivo & $\begin{array}{l}>3 \text { años } \\
\text { SDA } \\
\text { sin IRA a/b } \\
\text { ambulatorios }\end{array}$ & $\begin{array}{l}\text { Muestras } \\
\text { fecales }\end{array}$ & 527 & 9,1 & 5,3 & $\begin{array}{l}\text { HboV está presente en niños } \\
\text { con SDA con o sin IRA a/b. } \\
\text { Excreción fecal suma preocu- } \\
\text { pación por su transmisión. } \\
\text { Esta nueva especie de virus } \\
\text { es un patógeno entérico y } \\
\text { respiratorio }\end{array}$ \\
\hline $\operatorname{Lau}^{28}$ & 2007 & Hong Kong & Descriptivo & SDA & $\begin{array}{l}\text { Muestras } \\
\text { fecales }\end{array}$ & 1.435 & 2 & 52 & $\begin{array}{l}\text { Los humanos son infectados } \\
\text { por un solo linaje de } \mathrm{HBOV} \text {, } \\
\text { detectados en muestras respi- } \\
\text { ratorias y entéricas }\end{array}$ \\
\hline $\operatorname{Lee}^{3}$ & 2007 & Corea & Descriptivo & $\begin{array}{l}>5 \text { años } \\
\text { SDA } \\
\text { hospitalizados }\end{array}$ & $\begin{array}{l}\text { Muestras } \\
\text { fecales }\end{array}$ & 962 & 0,8 & 62,5 & $\begin{array}{l}\text { Este estudio sugiere menor rol } \\
\text { en las gastroenteritis } \\
\text { Recomienda estudios que } \\
\text { incluyan controles asintomáti- } \\
\text { cos y muestras respiratorias de } \\
\text { niños con SDA para definir su } \\
\text { rol entérico }\end{array}$ \\
\hline $\mathrm{Mei}^{30}$ & 2008 & China & Descriptivo & $\begin{array}{l}<5 \text { años } \\
\text { hospitalizados }\end{array}$ & $\begin{array}{l}\text { Muestras } \\
\text { fecales }\end{array}$ & 1.216 & 5,5 & 77,6 & $\begin{array}{l}\text { A pesar de la alta tasa de } \\
\text { infección, esto no fue estadísti- } \\
\text { camente significativo para una } \\
\text { relación causal entre HBoV y } \\
\text { gastroenteritis en niños }\end{array}$ \\
\hline
\end{tabular}

Tabla 4. Estudios chilenos de HBoV en muestras respiratorias

\begin{tabular}{|c|c|c|c|c|c|c|c|c|c|}
\hline Autor & $\begin{array}{l}\text { Año de } \\
\text { publica- } \\
\text { ción }\end{array}$ & $\begin{array}{l}\text { País de } \\
\text { estudio }\end{array}$ & $\begin{array}{l}\text { Tipo de } \\
\text { estudio }\end{array}$ & $\begin{array}{l}\text { Criterios de } \\
\text { selección }\end{array}$ & $\begin{array}{l}\text { Tipo de } \\
\text { muestra }\end{array}$ & $\begin{array}{c}\text { n de } \\
\text { muestras }\end{array}$ & $\begin{array}{l}\text { Positividad } \\
\text { bocavirus } \\
(\%)\end{array}$ & $\begin{array}{c}\text { Coinfección } \\
(\%)\end{array}$ & Conclusión \\
\hline Flores $^{22}$ & 2007 & Chile & $\begin{array}{c}\text { Cohorte } \\
\text { prospectiva }\end{array}$ & $\begin{array}{l}\text { Niños }<5 \text { años } \\
\text { con síntomas ITR }\end{array}$ & $\begin{array}{l}\text { Hisopado } \\
\text { naso- } \\
\text { faríngeo }\end{array}$ & 256 & 24,2 & 74 & $\begin{array}{l}\text { Pesquisa de HBoV en niños } \\
\text { chilenos por RPC }\end{array}$ \\
\hline Vizcaya $^{23}$ & 2008 & Chile & $\begin{array}{l}\text { Caso- } \\
\text { control }\end{array}$ & $\begin{array}{c}\text { Niños }<5 \text { años con } \\
\text { y sin síntomas ITR }\end{array}$ & $\begin{array}{l}\text { Hisopado } \\
\text { naso- } \\
\text { faríngeo }\end{array}$ & 285 & $\begin{array}{c}\text { Sintomático: } \\
14 \\
\text { Asintomático: } \\
37,5\end{array}$ & - & $\begin{array}{l}\text { Pesquisa de HBoV similar } \\
\text { en niños }<5 \text { años con y sin } \\
\text { síntomas }\end{array}$ \\
\hline
\end{tabular}

ITR: Infección del tracto respiratorio 
tras de HNF de niños bajo de 5 años de edad con síntomas respiratorios agudos procedentes de atención ambulatoria y hospitalizados, entre enero y agosto del 2007. Las muestras fueron estudiadas por inmunofluorescencia directa, D-Ultra ${ }^{\mathrm{TM}}$ DFA Respiratory Virus y MPV (DHI, USA), para VRS, ADV, influenza A/B, parainfluenza 1, 2, 3, y MPVh; en las muestras negativas se buscó MPVh por RPC y todas las muestras fueron procesadas por RPC para $\mathrm{HBoV}$. Los resultados mostraron una detección de $\mathrm{HBoV}$ en $24,2 \%(62 / 256)$ de los paneles respiratorios; en $26 \%$ (16/62) HBoV correspondió al único agente identificado y en $74 \%(46 / 62)$ se encontró como co-infección con otros virus. Los síntomas más frecuentes fueron tos (98\%), fiebre $(89 \%)$, rinorrea $(89 \%) \mathrm{y}$, dentro de los síntomas digestivos, diarrea (24\%) y vómitos $(36 \%)$.

En el segundo estudio, C. Vizcaya y cols ${ }^{23}$ compararon la frecuencia de $\mathrm{HBoV}$ en muestras de HNF en niños $\leq 5$ años, con y sin síntomas respiratorios, por medio de RPC convencional. Entre agosto y noviembre de 2007 estudiaron 163 muestras de HNF en niños $\leq 5$ años con síntomas respiratorios y panel viral negativo (IFD para VRS, ADV, parainfluenza 1-2-3, influenza A y B y MPVh) y en pacientes $\leq 5$ años, sin síntomas respiratorios, que acudían a control sano u hospitalización para procedimientos o cirugías electivas. Se detectó $\mathrm{HBoV}$ en $14 \%$ (23/163) de los niños sintomáticos, y 37,5\% (6/16) de muestras positivas para $\mathrm{HBoV}$ en $\mathrm{HNF}$ de niños asintomáticos mediante RPC convencional y RPC en tiempo real, respectivamente. En dicho estudio, la pesquisa de $\mathrm{HBoV}$ fue similar en niños sintomáticos y asintomáticos. La alta portación de $\mathrm{HBoV}$ puede corresponder, por un lado, a permanencia en la vía aérea después de la infección primaria, o por otro, que $\mathrm{HBoV}$ se comporta como otros miembros de la familia Parvoviridae, los dependovirus, que requieren de la presencia de virus en forma simultánea, para producir sintomatología ${ }^{9}$. Ello pudiera explicar además el alto porcentaje de co-infección descrito en varios estudios ya citados anteriormente.

\section{Estudios de caracterización clínica}

Bocavirus se ha asociado a sintomatología respiratoria aguda alta (tos, fiebre, conjuntivitis, coriza, faringitis, laringitis y otitis), baja (neumonía, obstrucción bronquial, bronquiolitis, tos de tipo coqueluchoídea) y a descompensación de pacientes asmáticos ${ }^{24-26}$.

Se ha asociado a vómitos, diarrea y exantema máculoeritematoso localizado en tórax, tronco y cara $^{27}$. En estudios iniciales se describieron síntomas gastrointestinales en 11 a $24 \%$ de los pacientes, mientras que en estudios más recientes, realizados en pacientes hospitalizados por diarrea, se detectó en $0,8 \%$ de los casos, lo que sugiere un rol menor como agente etiológico de diarrea ${ }^{3,28-30}$. Se ha detectado también HBoV en el lavado bronco-alveolar (LBA) de un paciente inmunosuprimido con neumonía ${ }^{31}$.
La infección por $\mathrm{HBoV}$ ha sido descrita frecuentemente en niños de dos años con enfermedad aguda del tracto respiratorio superior e inferior, presentando características clínicas similares al VRS y MPVh, ocasionando una proporción similar de cuadros graves ${ }^{32}$. En adultos las infecciones agudas por $\mathrm{HBoV}$ son infrecuentes y se han observado en pacientes inmunocomprometidos, caracterizadas por síntomas respiratorios agudos. Destaca el porcentaje de co-infección con otros virus, 34,6 a 72\% en diversas series, lo que ha llevado a cuestionar su rol como patógeno respiratorio ${ }^{5,8,18,20}$.

Otros estudios muestran que $\mathrm{HBoV}$ ha sido identificado en $31 \%(5 / 16)$ de pacientes con enfermedad de Kawasaki sugiriendo que este virus podría tener un rol patogénico en algunos casos de esta patología ${ }^{33}$. Se han postulado mecanismos inmunopatológicos en la enfermedad de Kawasaki con participación de otros agentes virales como virus Epstein-Barr, ADV y citomegalovirus. En el caso de $\mathrm{HBoV}$, detectado en diversas muestras como suero, deposiciones y LCR, se plantea que podría ser responsable de infección sistémica y tener participación en la patogenia de esta enfermedad; sin embargo, la evidencia para ello es insuficiente, por lo tanto, se necesita confirmar estos hallazgos con otros estudios.

En radiografías de pacientes con $\mathrm{HBoV}$ se describe la presencia de infiltrados intersticiales, imágenes de consolidación, hiperinsuflación y atelectasias. El diagnóstico se realiza por RPC convencional y en tiempo real de ANF y LBA ${ }^{34}$.

\section{Conclusiones a la fecha}

Es discutible el rol patogénico de $\mathrm{HBoV}$, tanto en infecciones respiratorias como en infecciones gastrointestinales, ya que existe positividad para el virus en similar proporción en niños con y sin síntomas.

Muchas patologías infecciosas son de origen viral y sólo se conoce una fracción de los agentes virales, por lo que aún existen virus no identificados. Estos patógenos desconocidos podrían explicar numerosas enfermedades agudas y crónicas de etiología no precisada. Un aporte importante en la información científica ha sido la identificación de un virus respiratorio emergente: bocavirus humano, descrito hace sólo cuatro años, y desde entonces reportado en diferentes partes del mundo, permitiendo obtener información rápida acerca de sus características y logrando identificar el agente etiológico en patologías respiratorias, antes idiopáticas.

Bocavirus humano parece ser un virus respiratorio que infecta principalmente a edades tempranas, antes de los dos años, produciendo respuesta inmune que protege en edades mayores. Aún faltan estudios para concluir su rol como patógeno entérico. 
Los métodos diagnósticos actuales no son homologables entre sí, lo que hace difícil hacer comparaciones entre los datos obtenidos, por lo que se hace necesario estandarizar una técnica diagnóstica internacional para permitir cotejar los estudios.

El estudio de la patogenia viral necesita un modelo animal y un cultivo celular, aún ausentes, por lo que los avances en este aspecto están detenidos.

Muchas líneas de investigación en marcha permitirán obtener mayor información de este nuevo agente viral a futuro.

\section{Resumen}

Bocavirus humano (HBoV), virus de la familia Parvoviridae, descubierto por métodos moleculares el año
2005, ha sido reportado en muestras respiratorias, fecales, sanguíneas y urinarias, tanto en niños como en adultos. Se han reportado prevalencias que van desde $0,8 \%$ en muestras fecales de individuos con diarrea aguda hasta $19 \%$ en muestras respiratorias y sanguíneas. En niños asintomáticos se ha detectado hasta $43 \%$ de $\mathrm{HBoV}$ en muestras nasofaríngeas. En Chile, se ha detectado HBoV en muestras de hisopado nasofaríngeo en niños bajo 5 años de edad, con síntomas respiratorios, en 24,2\%, existiendo co-infección con otros virus en $74 \%$, y en niños asintomáticos bajo 5 años años se ha encontrado $37,5 \%$ de muestras positivas para $\mathrm{HBoV}$. Se discute el rol de $\mathrm{HBoV}$ como agente causal de enfermedades respiratorias y/o digestivas, debido a co-infección con otros microorganismos, dificultando determinar si HBoV participa como único agente infeccioso.

\section{Referencias}

1.- Allander T, Tammi M, Eriksson M, Bjerkner A, Tivelijung-Lindell A, Andersson B. Cloning of a human parvovirus by molecular screening of respiratory tract samples. Proc Natl Acad Sci USA 2005; 102: 12891-6.

2.- Allander T, Jartti T, Gupta S, Niesters H G, Lehtinen P, Osterback R, et al. Human bocavirus and acute wheezing in children. Clin Infect Dis 2007; 44: 904-10

3.- Lee J I, Chung J Y, Han T H, Song M O, Hwang E S. Detection of human bocavirus in children hospitalized because of acute gastroenteritis. J Infect Dis 2007; 196: 994-7.

4.- Vicente D, Cilla G, Montes M, Pérez-Yarza E, Pérez-Trallero E. Human bocavirus, a respiratory and enteric virus. Emerg Infect Dis 2007; 13: 636-7.

5.- Bastien N, Brandt K, Dust K, Ward D, Li Y. Human bocavirus infection, Canada. Emerg Infect Dis 2006; 12: 848-50.

6.- García-García M L, Calvo C, Pozo F, Pérez-Brena P, Quevedo S, Bracamonte T, et al. Human bocavirus detection in nasopharyngeal aspirates of children without clinical symptoms of respiratory infection. Pediatr Infect Dis J 2008; 27: 358-60.

7.- Longtin J, Bastien M, Gilca R, Leblanc E, de Serres G, Bergeron M G, et al. Human bocavirus infections in hospitalized children and adults. Emerg Infect Dis 2008; 14 : 217-21.

8.- Lindner J, Modrow S. Human bocavirus - A novel parvovirus to infect humans. Intervirology 2008; 51: 116-22.

9.- Jofré L. Virus respiratorios emergentes. Neumología-pediatrica.cl

10.- Rihkanen H, Rönkkö E, Nieminen T, Komsi K L, Räty R, Saxen H, et al. Respiratory viruses in laryngeal croup of young children. $\mathrm{J}$ Pediatr 2008; 152: 661-5.

11.- Kahn J S. Newly discovered respiratory viruses: significance and implications. Curr Opin Pharmacol 2007; 7: 478-83.

12.- Albuquerque M, Rocha L, Benati F, Soares C, Maranhao A, Ramírez M, et al. Human bocavirus infection in children with gastroenteritis. Emerg Infect Dis 2007; 13: 1756-8.

13.- Mackay I. Human bocavirus: Multisystem detection raises questions about infection. J Infect Dis 2007; 196: 968-70.

14.- Maggi F, Andreoli E, Pifferi M, Meschi S, Rocchi J, Bendinelli M. Human bocavirus in Italian patiens with respiratory diseases. J Clin Virol 2007; 38: 321-5.

15.- Schenk T, Huck B, Forster J, Berner R, Neumann-Haefelin D, Falcone V. Human bocavirus DNA detected by quantitative realtime PCR in two children hospitalized for lower respiratory tract infection. Eur J Clin Microbiol Infect Dis 2007; 26: 147-9.

16.- Kesebir D, Vázquez M, Weibel C, Shapiro E, Ferguson D, Landry M, et al. Human bocavirus infection in young children in the United States: Molecular epidemiological profile and clinical characteristics of a newly emerging respiratory virus. J Infect Dis 2006; 194: 1276-82.

17.- Monteny M, Niesters H, Moll H, Berger M. Human bocavirus in febrile children, the Netherlands. Emerg Infect Dis 2007; 13: 180-2.

18.- Chung J, Hee Han T, Keun Kim C, Woo Kim S. Bocavirus infection in hospitalized children, South Korea. Emerg Infect Dis 2006; 12: 1254-6.

19.- Xiao-Wang Q, Zhao-Jun D, Zheng-Yu Q, Zhi-Ping X, Han-Chun G, Wen-Pei L, et al. Human bocavirus infection, People's Republic of China. Emerg Infect Dis 2007; 13: 165-8.
20.- Arnold J, Singh K, Spector S, Sawyer M. Human bocavirus: Prevalence and clinical spectrum at a children's hospital. Clin Infect Dis 2006; 43: 283-8.

21.- Kupfer B, Vehreschild J, Cornely O, et al. Severe pneumonia and human bocavirus in adult. Emerg Infect Dis 2006; 12: 1614-6.

22.- Flores J C, Araos R, Montecinos L, Perret C, Wilhelm J, Azócar T. Bocavirus humano un nuevo virus respiratorio: Descripción clínica y epidemiológica en Santiago, Chile, 2007. Libro de Resúmenes XXIV Congreso Chileno de Infectología. Pucón, noviembre 2007. Resumen oral CO-26: pág. 44.

23.- Vizcaya C, Ferrés M, Montecinos L, Godoy P, Azócar T, Flores J C, et al. Búsqueda de bocavirus humano (HBoV) en niños menores de 5 años sin síntomas respiratorios. Libro de Resúmenes XXV Congreso Chileno de Infectología, La Serena, 5-8 noviembre 2008. Resumen oral CO-40: pág. 57.

24.- Regamey N, Frey U, Deffernez C, Latzin P, Kaiser L. Isolation of human bocavirus from Swiss infants with respiratory infections. Pediatr Infect Dis J. 2007; 26: 177-9.

25.- Arden K E, McErlean P, Nissen M D, Sloots T P, Mackay I M. Frequent detection of human rhinoviruses, paramyxoviruses, coronaviruses, and bocavirus during acute respiratory tract infections. J Med Virol 2006; 78: 1232-40.

26.- Lin F, Zeng A, Yang N, Lin H, Yang E, Wang S, et al. Quantification of human bocavirus in lower respiratory tract infections in China. Infect Agent Cancer 2007; 31 (2): 3

27.- Weissbrich B K, Neske F F, Schubert F F, Schubert J J, Tollman F F, Balth K K, et al. Frequent detection of bocavirus DNA in German children with respiratory tract infections. BMC Infect Dis 2006; 6: 109.

28.- Lau S K, Yip C C, Que T L, Lee R A, 
Au-Yeung R K, Zhou B, et al. Clinical and molecular epidemiology of human bocavirus in respiratory and fecal samples from children in Hong Kong. J Infect Dis 2007; 196: 986-93.

29.- Wei-xia Ch, Yu J, Zhao-jun D, Zi-qian X, Hong-mei Q, Qing Z, et al. Human bocavirus in children hospitalized for acute gastroenteritis: A case-control study. Clin Infect Dis 2008; 47: 161-7.

30.- Jie-Mei Y, Dan-di Li, Zi-Quian X, Wei-Xia Ch, Quing Z, Hui-Ying L, et al. Human bocavirus infection in children hospitalized with acute gastroenteritis in China. J Clin Virol 2008; 42: 280-5.

31.- Fry A M, Lu X, Chittaganpitch M, Peret T, Fischer J, Dowell S F, et al. Human bocavirus: a novel parvovirus epidemiologically associated with pneumonia requiring hospitalization in Thailand. J Infect Dis 2007; 195: 1038-45.

32.- Manning A, Russell V, Eastick K, Leadbetter G H, Hallam N, Templeton K, et al. Epidemiological profile and clinical associations of human bocavirus and other human parvoviruses. J Infect Dis 2006; 194: 1283-90.

33.- Catalano- Pons C, Giraud C, Rozenberg F, Meritet JF, Lebon P, Gendrel D. Detection of human bocavirius in children with Kawasaki disease. Clin Microbiol Infect 2007; 13: 1220-2.

34.- Xiaoyah L, Chittaganpitch M, Olsen S J, Mackay I M, Sloots T P, Fry A L, et al. Real time PCR assays for detection of bocavirus in human specimens. J Clin Microbiol 2006; 44: 3231-5. 